\title{
ТЕОРИЯ КОГНИТИВНЫХ ПРЕЦЕДЕНТОВ
}

(Олег Лещак и Светлана Лещак «Когнитивные прецеденты в художественном идиостиле Бориса Гребенщикова: общество и сакральная сфера», Wyd. UJK Kielce 2020, 288 s.)

\section{Владимир ЗАИКА}

\author{
доктор филол. наук, \\ профессор Новгородского государственного университета \\ им. Ярослава Мудрого, Россия \\ https://orcid.org/0000-0002-2206-772X
}

\section{DOI 10.25128/2304-1222.20.51.11}

\begin{abstract}
The article is a review of a monograph by Polish linguists Oleg Leszczak and Swietlana Leszczak, devoted to the analysis of cognitive precedent units of a socio-ethical and sacred nature, characteristic of the idiostyle of the Russian rock poet Boris Grebenszczikov. The innovative theoretical nature of the research and the thoroughness of the analysis of the material are noted.
\end{abstract}

Keywords: Boris Grebenszczikov, cognitive precedent units, Oleg Leszczak, Swietlana Leszczak.

Стаття є рецензією монографії польських лінгвістів Олега Лещака і Світлани Лещак, присвяченої аналізу когнітивних прецедентних одиниць соціально-етичного та сакрального характеру, характерних для ідіостилю російського рок-поета Бориса Гребенщикова. Відзначається новаторський теоретичний характер дослідження і ретельність зробленого аналізу матеріалу.

Ключові слова: Борис Гребенщиков, когнітивні прецедентні одинищі, Олег Лещак, Світлана Лещак.

Artykuł jest recenzją monografii polskich językoznawców Olega Leszczaka i Swietlany Leszczak, poświęconej analizie kognitywnych jednostek precedensowych o charakterze społeczno-etycznym i sakralnym, charakterystycznych dla idiostylu rosyjskiego rock-poety Borisa Grebenszczikowa. Zwraca się uwage na nowatorski teoretyczny charakter badań oraz dokładność analizy materiału.

Slowa kluczowe: Boris Grebenszczikow, kognitywne jednostki precedensowe, Oleg Leszczak, Swietlana Leszczak.

Монография является продолжением работы «Когнитивные прецеденты в песенном творчестве Бориса Гребенщикова: природа и человек» (Кельце 2019) и завершением воссоздания идиостилевой художественной картины мира поэта. Предмет исследования система образов, об эффективности которых говорит их заметная слушателям и исследователям повторяемость.

Структурируя художественную картину мира, авторы оперируют понятием когнитивное пространство, подразумевая под ним некую совокупность, включающую наряду с концептами также мыслительные процедуры. Такие когнитивные пространства определяют тему, содержание текста, а также структуру всей художественной картины мира. Авторы подчеркивают прагматический характер концептов и уточняют, что в этой роли могут быть и понятия, и символы, и образы. Картина мира в предложенной авторами схеме состоит из 
когнитивных пространств природа, общество и сакральная сфера, которые встроены в макропространство человек.

В рецензируемой монографии рассмотрению концептуализации когнитивных пространств предшествуют изложение теоретических оснований (о когнитивных прецедентах и о художественном дискурсе). Такая композиционная особенность показала свою эффективность в предыдущей монографии.

Важнейшее исходное положение авторов - картина мира кибернетична. Несомненно, поэтическая картина мира рукотворна. В том смысле, что создана осознанно и целенаправленно конкретным творческим субъектом. Целенаправленность этой рукотворности нужно уточнить. Поэт пишет тексты, имея целью создание конкретного художественного мира, представленного этим текстом. Однако создание картины мира не является целью поэта. Художественная картина мира - побочный продукт создания художественного мира, изображаемого в тексте, в процессе чего называются реалии, процессы, события и другие составляющие этого художественного мира. Разумеется, при создании альбома создание того или иного текста или включении его в альбом, его понятийная и образная системы согласуются с такими же системами других текстов альбома, но эта оглядка на семантику и прагматику созданных текстов делается не для упорядочения идиостиля, но для изображения конкретного художественного мира.

Весьма важным для рассмотрения прецедентности считаю сделанное авторами разграничение синергии и кибернетизма. В случаях сознательного применения автором той или иной единицы как системного элемента идиостиля имеет место кибернетизм. Синергетично автор реализует когнитивные прецеденты и модели их использования, не отдавая себе отчет в том, что это «не плод его актуального творческого воображения, а воспроизводимые информационные функции его памяти». Синергия в процессах порождения речи и перестройки тезауруса известна многим по ситуации, когда некое удачно подобранное слово становится часто употребляемым, причем частотность его, может быть, даже раздражает говорящего, но слово выскакивает как-бы помимо воли говорящего и контроль его употребления требует определенных усилий.

Очень важным представляется отношение исследователей к каузальному плану создания художественного мира (синергии). Проблематичность этого плана даже не в том, что невозможно «затереть границы форм жизнедеятельности» или освободиться от «синергетических уз»: этот синергетический плен очевиден. Проблема в том, что этот каузальный план, присутствующий (создаваемый и воссоздаваемый) в художественном мире благодаря неявным (фоновым и/или личностным) знаниям носителя языка просто исчезает вместе с носителями этих неявных знаний. «Восстановление» этого плана посредством подробных комментариев не может обеспечить художественный эффект, потому что неявные 
знания должны быть именно неявными, чтобы быть задействованными при воссоздании художественного мира по вербализованным реалиям, процессам и пр. Это понятно даже при восприятии таких простых, казалось бы, фигур как ирония (см. подробные комментарии к фрагментов песни «Из Калинина в Тверь» в параграфе «Концептуализация общественнополитических отношений и идеологии»).

Прежде чем рассматривать специфику художественной концептуализации когнитивных пространств авторы определяют особый функциональный статус категорий места, границы, движения, войны и рассматривают три макроконцепта категории границы. В монографии рассмотрены основные концептуальные составляющие категории границы и мотивы ее преодоления. Доказательно установлены коннотации семантики предела: тревожность нахождения по эту сторону и беспечность нахождения по ту сторону, выявлены и разъяснены связи между макроконцептами (например, предел) и мотивами (например, выход за предель).

В самом общем виде характеристика прецедентов реализуется так: эксплицируется отношение к явлению, определенное авторами по известной совокупности песен, в том числе и за счет прецедентности, затем приводятся (при наличии) сведения об отношении Б.Гребенщикова к явлению, а затем проводится доказательный анализ.

Нужно отметить, что весьма содержательно вербализована обобщенная семантика примеров воплощения той или иной идеи. При этом авторы применяют два способа пояснения: блоки примеров, иллюстрирующих то или иное положение, и комментированные цитаты, как, например, цитаты применения стекла как преграды: «Жили впотьмах, ждали ответа; Кто там внизу - а это лишь стекло (Удивительный мастер Лукьянов) - т. е. в мире обыденности (стекло как символ ограничения свободы при видимости ее наличия» (с. $45)$.

Тщательное наблюдение многочисленных классифицированных контекстов позволяет авторам выяснить устойчивые приемы изображения, например, мотив отражения в зеркале и в целом свойства зеркала в концептосфере Б.Г.

Надо заметить и то, что авторы для разъяснения семантики и прагматики когнитивных прецедентов, а также для подтверждения своих рассуждений активно используют высказывания Б.Гребенщикова по поводу рассматриваемых предметов и явлений. Конечно, в интервью человек проявляет себя как есть, утверждения характеризуются прямотой, местами даже с неким налётом поучения (который иногда проявляется и в песнях). Впрочем, при «подключении» к анализу прецедентов, создающих художественную картину мира, высказываний гражданина Б.Гребенщикова, авторы всегда обращают внимание на различия его с повествующим субъектом текстов, как например, это сделано при описании функциональных особенностей макроконцепта любовь. 
На основании того, что изображаемый человек в творчестве Б.Гребенщикова реализует жизненный опыт в общественно-этической деятельности, авторы рассматривают соответствующее когнитивное пространство, в «пределах» которого герой занят решением морально-этических проблем. Авторы показывают, что герой изображается в тройственном противостоянии концептуализированным обобщенным субъектам: общественному мнению, культурно-цивилизационной системе и государству. Замечу, что в этом параграфе материал был параметризован по весьма сложным «величинам», вроде стратегии общественного поведения при столкновении с выделенными субъектами (социумом, народом, властью), которое может быть трояким: приспособление, пассионарность и т.д. Приведенные контексты позволили прийти к интересным выводам, например, о возможностях пути пассионариев: столкновение или андеграунд.

Тщательный анализ позволил исследователям выяснить особенности мировоззрения поэта и прописать их как положения: «Жизненная суета и борьба с мельницами - это ... не более, чем хильй закос под любовь». «Мысль и слово ... гораздо более эффективное орудие совершенствования себя и окружения, чем насилие», «Песня, поэтический текст может быть не худшим и не менее сильным способом противодействия злу, чем бунт или политическая борьба» (с. 68-69), а также сделать вполне обоснованный вывод о провозглашенной Б.Г. отрешенности творческого самосовершенствования «без оглядки на общественные турбуленции» (с. 69).

Рассматривая концептуализацию сферы общественной морали, авторы выделили основные ценности этической системы лирического героя: стремление к духовности, честность перед самим собой, порядочность по отношению к другим, спокойствие и гармонию. Наряду с этими ценностями отмечены в художественной картине мира поэта и негативные ипостаси общественной среды, деградирущие институции: религия, наука, и с ней в этом ряду цุирк «как гротескный символ современной морали» (с. 77).

В процессе анализа когнитивных пространств авторы обращают внимание на продуктивные в творчестве поэта мотивы. Таковым, например, является мотив движения по пути как динамический образ общественно-этической жизни. Общественную жизнь Б.Г. изображает как движение. В рамках этой установленной авторами модели презентации подробно описаны несколько экспликативных схем. Нужно отметить используемое авторами емкое понятие экспликативной схемы, позволяющее включить и предмет изображения (некие явления художественного мира созданного Б.Г.) и средства изображения - номинативные средства и приемы с учетом рассматриваемой прецедентности (повторяющейся реалии, действия, события, ситуации), что уже выражено в наименованиии схемы, например: «Движение по дороге как изображение бездуховного быта: Прекраснылй дилетант на пути в гастроном, того ли ты ждал? (Прекрасный дилетант) (с. 87), танец как изображение суеты 
или как выход из этой суеты» (с. 89-90). Далее подробный анализ позволяет выявить и особенности танца как макроконцепта со сложными ценностными характеристиками

Заметной особенностью последовательного и подробного описания когнитивных прецедентов идиостиля является множественное цитирование, сопровождающее почти каждое из положений. Объемные списки прецедентов иллюстрируют особенности реалий, используемых в качестве сквозных образов, а также изобразительные особенности компонентов этих реалий или ситуаций их использования (поезд, колесо, опоздание на поезд).

В ряде случаев авторы вербализуют прямым текстом то, что выражено в картине мира Б.Г. тем или иным образом, например, мысль о распаде общества: «общество распадается не только тогда, когда происходит его атомизация, каждый заботится лишь о собственных потребностях и начинается «война всех со всеми». Второй причиной распада современного общества оказывается бездуховность и пошлость, отсутствие у человека культурных потребностей, а также бездумность, инфантилизм и конформизм, подверженность воздействию масс-медиа и общественных стереотипов» (с. 79).

При рассмотрении семантики выразительных средств авторы используют своего рода многократное обобщение: во-первых, дается название того, что представлено, например, экспликативной схемой: поиск нравственных решений как поиск дороги или выхода. Затем дается более конкретизированное объяснение этой схемы с участием субъекта или субъектов и уже к этой конкретизации приводится значительное количество иллюстраций, в которых сам пример показывает реализацию этой экспликативной схемы в указанном варианте.

Большинство отдельных примеров не разъясняется, но приводится обобщение, касающееся свойств художественной картины мира Б.Г. в целом, тех или иных особенностей индивидуального когнитивного тезауруса, например, обобщение о метафизическом характере истоков нравственности для Б.Г. Разъясненные же примеры показывают, что списки прецедентов вполне обоснованы, например, фрагмент об образе «Пьяного матроса» (с. 112).

Прецедентность, уже как таковая, провоцирует на обобщение на основе отсылки к сходному, находящемуся вне воспринимаемого линейного текста. Поэтому в процессе восприятия текста узнаваемое выразительное слово, экспликативная схема и др. прецеденты нарушают эстетическое переживание художественной речи при создании целостной картины. Но можно на эту ситуацию посмотреть по-иному. Следующее соображение имеет отношение к вопросу, затронутому авторами во втором введении (о художественном дискурсе). На вопрос, предзадан ли код тексту, если речь идет о коде изобразительном, возникающем в процессе создания текста, я отвечаю отрицательно. В ситуации эстетической реализации этнического языка, разумеется, этот этнический язык предзадан, но идиостиль возникает в процессе творчества. 
Однако обратим внимание на другое. Рецензируемое исследование убеждает в возможности рассматривать воспринимаемый повтор как особого рода эстетическую реакцию. Эта реакция существенно отличается от обычной реакции переживания создаваемого художественного мира (в обычных случаях восприятия художественной речи, в том числе и песни). Можно сказать, что в случае прецедентности воспринимающий воссоздает более сложный художественный мир, элементами которого являются не только реалии (явления, события) и лирический субъект (о чем неоднократно было сказано), но язык, индивидуально (и изобразительно) скорректированный этнический язык. Поклонник, почитатель, знающий творчество поэта, воссоздает и этот третий элемент художественного мира - художественный язык поэта, испытывая переживание эстетически более сложное, чем случайный слушатель.

Описывая концептуализацию культурно-цивилизационных особенностей советского и российского общества посредством выявления маркеров русскости и/или советскости, авторы установили специфическую патриотичность текстов Б.Г. Выявлен пространственный изобразительный эклектизм, который можно понимать и как сюрреалистичность (см. комментарии образных элементов в Гарсон номер два, Зимняя роза и др.). Установлено, что «практически нет текстов, совершенно лишенных прямых или косвенных связей с российской культурной средой» (с. 102). Такие связи обеспечены и онимами (Кострома), и реалиями (ларек), и языковыми маркерами (охренеть). Выясняются также изменения в репрезентации России, в частности, конкретизация объекта критики: это не столько негативные черты российской жизни, сколько власть как организатор бед (с. 126).

Авторы назвали рассматриваемое явление «Локодицея» общественной жизни. Мне кажется, это не вполне локодицея, потому что здесь нет собственно -дицеи. Русскость у Б.Г. оказывается не благостью, а, как подмечают исследователи, средоточием недостатков, пороков, маразма, зла. Думаю, термин правтльно взят в кавычки, потому что картина апокалипсиса, которую увидели авторы четко изображенной в текстах Б.Гребенщикова - это отнюдь не локдицея, несмотря на то, что вообще-то Россия (российское общество в совокупности с его культурно-цивилизационной спецификой) не сводима к сумме его безнравственных проявлений (эмпирии), поскольку содержит в себе некую имманентную сущность - высокий нравственный потенциал. Впрочем, среди явных признаков светопреставления автор (Б.Гребенщиков) неплохо себя чувствует, вероятно, вполне реализовав этот самый потенциал.

При семантизации этих групп прецедентного тезауруса авторы тоже привлекают прямые высказывания (в некоторых усматривается «притчевая манера») по поводу изображаемого мира, бардака и неустроенности. Как если бы разъяснения для косных, агрессивных, страдающих безвкусицей сограждан. В исследовании авторы сверяют мысли 
Б.Г. с мыслями Б.Гребенщикова, находя и подчеркивая сходства и различия, например во взглядах на власть и политику (с. 128). Работа содержит пространные комментарии довольно ясных высказываний гражданина (и философа) Б.Гребенщикова о государстве Россия, на фоне которых рассматриваются когнитивные прецеденты, например высказывания лирического героя по поводу взаимоотношений власти и современного общества. Интерпретация тестов поэта иногда сопровождается весьма содержательными отступлениями, например о фидеизме и иррационализме российской этнической ментальности (с. 115-116).

Особенностью композиции рецензируемой работы является наличие концептуальных отступлений, которые обусловлены тем, что некий концепт трактуется исследователями как расширивший свои функционально-прагматические возможности и работающий в изобразительном отношении не только как маркер того или иного элемента изображаемого мира, но и как мотив, понимаемый авторами как схема события (таковы, например, отступления о концептах движение и война или о концептуальном мотиве «движение»). Так, рассмотрены экспликативные схемы изображения невоенной жизни с помощью концепта война, что потребовало разграничивать войну в прямом значении (поскольку это маркер власти) и метафорическом (отношения народа и власти или общественной нравственности).

Востребованность когнитивного прецедента определяет и количество, и разнообразие материала, а также, как показывает исследование, его функционально прагматическое разнообразие, изобразительная сложность.

В главе «Художественная концептуализация когнитивного пространства “сакральная сфера"» авторы определили сложную структуру когнитивного пространства и установили, как когнитивные прецеденты раскрывают особенности изображения трансцендентных проявлений и духовного роста, исходя при этом из того, что «трансцедентная позиция Гребенщикова, а в еще большей степени позиция поэта Б.Г. гораздо шире любой религиозной платформы и носит не индуктивно-диалогический, а дедуктивно-универсальный характер» (с. 168).

Преодолевая сложности, которые вызваны тем, что названо «религиозной эклектикой», а также органичным сосуществованием в «едином сакральном пространстве» разных трансцендентных картин мира, которые, кроме всего прочего, связаны с миром природы и общественной сферы, авторы исследуют художественное изображение сакрального в текстах Б.Гребенщикова, отдельно рассматривая семантику сакральной сферы (особенности изображения тренсцендентных проявлений) и ее прагматику (сакральную аксиологизацию духовного роста). В рассуждениях о том, как концептуализируются трансцендентные проявления, авторы настроены против понимания Б.Гребенщикова как религиозного мистика и религиозного поэта. 
Отличное знание корпуса позволило авторам выявлять не только частотные прецеденты (мистические события) едва и заметные, но содержательно существенные прецеденты, как, например, указание на наличие чего-то большего, чем кажется, в реалиях и событиях. Проанализированы разновидности сакральных знаков: имена, различные числа, а также сакральные вещества и вещи (лед, соль, пепел, ключи, свечи и др.). Интересны различные частные интерпретации, например, рассмотрение формулы три всегда четыре как мировоззренческой установки на единство человека и триединого бога (с. 182). Как прагматически существенные в художественной картине мира Б.Г. рассмотрены также сакральные существа, в частности, те, которые не распознаны соучастниками описываемых событий и неясны при обращении к ним лирического героя. Рассмотрены ангел (в разных ипостасях), душа и др. антропоморфные сакральные существа, в том числе супергерои и антигерои.

С наибольшей подробностью описаны особенности феминного божества как элемента идеостилевой картины мира поэта с прагматической двойственностью: божественностью/демоничностью (с. 207). Вывод о том, что концептуализированные понятия божества (маскулинного, феминного и амбивалентного в половом отношении) является ядром когнитивного пространства идиостилевой картины мира Б.Г. и что в это ядро явно не входит собирательное представление о богах как группе божественных сущностей, можно считать вполне обоснованным.

Важен аспект рассмотрения когнитивных прецедентов, позволяющий увидеть в разных когнитивных пространствах картины мира прагматически противоположные изобразительные явления; анализ позволяет говорить, например, о наличии особой концептуальной изобразительной модели профанации сакрального (с. 233).

Последнее, что описывают исследователи в монографии - то, как концептуализировано художественное творчество. Хотя оно, по данным исследователей, не образует в картине мира Б.Г. самостоятельного когнитивного пространства, находясь в пределах сакральной сферы, но при этом не подчинено ни религии, ни философии, и является средством самосовершенствования человека.

Таким образом, гипотеза авторов относительно предпочтительности дискурсивноконцептуального анализа художественной картины мира и идиостиля поэта для изучения творчества Б.Г. вполне подтверждена исследованием.

Многие выводы являются результатом многократных прочтений, «внимательного слежения за контекстом», учета иных (прежних) контекстов, учета нехудожественных высказываний автора. Кроме того, нужно отметить, что что авторы не пропускают различных спорных интерпретаций как конкретных концептов, экспликативных схем (модельных изображений тех или иных реалий, явлений), так и отдельных фрагментов песен. 
Авторы подробным семантическим и прагматическим анализом показали сложность и уникальность художественной картины мира поэта, тем самым сделали «одно из аналитических предложений» для заинтересованных исследователей творчества Б.Гребенщикова и/или исследователей художественного творчества как такового.

Категориальный аппарат исследования, апробированный на сложном и разнообразном материале, может быть использован для работы над любым индивидуальным когнитивным тезаурусом.

\section{ЛИТЕРАТУРА}

Лещак, О. Лещак, С. (2020), Когнитивные прецеденты в художественном идиостиле Бориса Гребенщикова: общество и сакральная сфера, Kielce: UJK [Leszczak, O., Leszczak, S. (2020), Kognitivnie pretsedenti v khudozhestvennom idiostile Borisa Grebensshikova: obsshestvo i sakralnaya sfera, Kielce: UJK]. 